University of Nebraska - Lincoln

DigitalCommons@University of Nebraska - Lincoln

\title{
A sediment ecotoxicity assessment platform for in situ measures of chemistry, bioaccumulation and toxicity. Part 1: System description and proof of concept
}

\author{
G. Allen Burton Jr. \\ University of Michigan - Ann Arbor, burtonal@umich.edu \\ Gunther Rosen \\ Space and Naval Warfare Systems Center Pacific \\ D. Bart Chadwick \\ Space and Naval Warfare Systems Center Pacific \\ Marc S. Greenberg \\ U.S. Environmental Protection Agency \\ W. Keith Taulbee \\ Great Lakes Environmental Center \\ See next page for additional authors
}

Follow this and additional works at: https://digitalcommons.unl.edu/usnavyresearch

Burton, G. Allen Jr.; Rosen, Gunther; Chadwick, D. Bart; Greenberg, Marc S.; Taulbee, W. Keith; Lotufo, Guilherme R.; and Reible, Danny D., "A sediment ecotoxicity assessment platform for in situ measures of chemistry, bioaccumulation and toxicity. Part 1: System description and proof of concept" (2012). U.S. Navy Research. 29.

https://digitalcommons.unl.edu/usnavyresearch/29

This Article is brought to you for free and open access by the U.S. Department of Defense at DigitalCommons@University of Nebraska - Lincoln. It has been accepted for inclusion in U.S. Navy Research by an authorized administrator of DigitalCommons@University of Nebraska - Lincoln. 


\section{Authors}

G. Allen Burton Jr., Gunther Rosen, D. Bart Chadwick, Marc S. Greenberg, W. Keith Taulbee, Guilherme R. Lotufo, and Danny D. Reible 


\title{
A sediment ecotoxicity assessment platform for in situ measures of chemistry, bioaccumulation and toxicity. Part 1: System description and proof of concept
}

\author{
G. Allen Burton Jr. ${ }^{\mathrm{a}, *}$, Gunther Rosen ${ }^{\mathrm{b}}$, D. Bart Chadwick ${ }^{\mathrm{b}}$, Marc S. Greenberg ${ }^{\mathrm{c}}$, \\ W. Keith Taulbee ${ }^{\mathrm{d}}$, Guilherme R. Lotufo ${ }^{\mathrm{e}}$, Danny D. Reible ${ }^{\mathrm{f}}$ \\ ${ }^{a}$ School of Natural Resources and Environment, University of Michigan, Ann Arbor MI 48109, USA \\ ${ }^{\mathrm{b}}$ Environmental Sciences Branch, Space and Naval Warfare Systems Center Pacific, San Diego, CA 92152, USA \\ ${ }^{c}$ U.S. Environmental Protection Agency, Emergency and Remedial Response, 2890 Woodbridge Ave, Edison NJ 08837, USA \\ ${ }^{\mathrm{d}}$ Great Lakes Environmental Center, 1295 King Ave., Columbus, OH 43212, USA \\ ${ }^{\mathrm{e}}$ Engineer Research and Development Center, US Army Corps of Engineers, 3890 Halls Ferry Road, Vicksburg MS 39180-6199, USA \\ ${ }^{\mathrm{f}}$ Civil Engineering, University of Texas, Austin TX 78712, USA
}

\section{A R T I C L E I N F O}

\section{Article history:}

Received 6 June 2011

Received in revised form

8 November 2011

Accepted 10 November 2011

\section{Keywords:}

Sediment contamination

Risk assessment

In situ

\begin{abstract}
A B S T R A C T
In situ-based testing using aquatic organisms has been widely reported, but is often limited in scope and practical usefulness in making decisions on ecological risk and remediation. To provide this capability, an integrated deployment system, the Sediment Ecotoxicity Assessment (SEA) Ring was developed, which incorporates rapid in situ hydrological, chemical, bioaccumulation, and toxicological Lines-of-Evidence (LoE) for assessing sediment and overlying water contamination. The SEA Ring system allows for diverassisted, or diverless, deployment of multiple species of ecologically relevant and indigenous organisms in three different exposures (overlying water, sediment-water interface, and bulk sediment) for periods ranging from two days to three weeks, in a range of water systems. Measured endpoints were both sublethal and lethal effects as well as bioaccumulation. In addition, integrated passive sampling devices for detecting nonpolar organics (solid phase micro-extraction fibers) and metals (diffusive gradients in thin films) provided gradient measures in overlying waters and surficial sediments.
\end{abstract}

(c) 2011 Elsevier Ltd. All rights reserved.

\section{Introduction}

Traditional approaches for assessment of contaminated sediments and verification of remedial measures generally rely on laboratory-based exposures for toxicity and bioaccumulation coupled with bulk sediment chemical characterization and benthic community structure characterization (Wenning et al., 2005). While these laboratory methods provide a high degree of experimental control, often times this comes with a significant loss of representativeness due to excessive manipulation and loss of the natural conditions and integrity of the samples and exposures (Adams et al., 2005). In addition, strong linkages between these lines-of-evidence are often absent and so uncertainty often arises as a result of conflicting results (Burton et al., 2002). These issues are especially important where the exposure pathway cannot be adequately reproduced in the laboratory, when the exposure is transient in time, or where an in situ remedy is utilized. Examples of these instances include sites where groundwater discharge or tidal pumping of

\footnotetext{
* Corresponding author.

E-mail address: burtonal@umich.edu (G.A. Burton).
}

porewater are present, sites where stormwater or transient resuspension events occur, and sites where reactive amendments or caps are utilized. In situ exposure approaches offer one alternative to these traditional strategies. In situ methods have been demonstrated for sediment assessment for a wide variety of organisms, endpoints and environmental settings (Crane et al., 2000; Geffard et al., 2001; Greenberg et al., 2002; Ringwood and Keppler, 2002; Anderson et al., 2004; Phillips et al., 2004; Adams et al., 2005; Burton et al., 2005). In certain situations, in situ methods are the only viable alternative to characterize transient exposures. Nevertheless in situ methods have been slow to gain acceptance in regulatory programs primarily due to perceived lack of experimental control, the complexity and high degree of expertise associated with the methods, and the more challenging aspects of the logistics for the field-based assessment methods as compared to laboratory-based methods. In addition, in situ toxicity or bioaccumulation methods have lacked an inherent integration with other chemical lines-ofevidence. To improve this situation, systems are needed that improve the level of experimental control for in situ methods, simplify and standardize the methods to the degree possible, and provide the ability to integrate chemical and biological lines-of- 
evidence. Here we present the description and initial proof of concept for such an integrated device termed the Sediment Ecotoxicity Assessment (SEA) Ring. Part II of this series provides additional evidence of the utility of the device and other physicochemical tools resulting in an integrated multiple line of evidence approach at a contaminated sediment site where time-varying stressors were of potential concern (Rosen et al., 2012).

\section{Materials and methods}

\subsection{Preliminary testing}

\subsubsection{Equilibration of in situ chamber water}

A dye study was conducted using chambers described by Burton et al. (2005). Exposure chambers varied in screen size, ranging from 80 to $300 \mu \mathrm{m}$. Smaller $(25 \mu \mathrm{m}$ mesh) "drum" style chambers, constructed according to Phillips et al. (2004), were also placed into a subset of the $80 \mu \mathrm{m}$ chambers to investigate water exchange with the external environment for use with particularly small and fragile (i.e., mussel embryos) organisms. All 80-300 $\mu \mathrm{m}$ exposure chambers were filled with a solution containing $1 \mathrm{~mL}$ red dye food coloring and $500 \mathrm{~mL}$ deionized (DI) water. The chambers were placed into a 17 gallon, high density polyethylene (HDPE) tub filled with DI water. An aquarium pump maintained flow at a rate of 100 gallons per hour (GPH). Two replicates for each mesh size were removed from the tub at each time interval and the absorbance of dye remaining was measured using a HACH DR/2400 spectrophotometer.

Separately, an alternative embryo-scale exposure chamber design using glass scintillation vials was evaluated. These chambers are typically used in laboratory embryo-larval development tests (USEPA, 1995), and can be examined directly on an inverted microscope, thus eliminating the need for transfer steps at the conclusion of the test. The solid plastic screw caps from these chambers were modified with $25 \mu \mathrm{m}$ Nitex mesh screen covering a drilled out opening with a diameter of approximately $1.5 \mathrm{~cm}$. This design was successful for laboratory-based microcosm exposures with Mytilus galloprovincialis embryos (Rosen and Lotufo, 2007, 2010). To examine site water equilibration of this chamber design, a $20 \mathrm{~L}$ polycarbonate tank was filled with natural seawater $(33 \%)$. Subsequently, 27 exposure chambers were filled with deionized water $(0 \%)$ and placed in the tank. Three replicate vials were removed at 9 different sampling points over a period of approximately $24 \mathrm{~h}$, and salinity of the contents measured. The experiment was conducted under two flow conditions: static and under a continuous flow rate of $100 \mathrm{GPH}$ using a MarineLand Bio-Wheel Pro30 aquarium filter.

\subsubsection{Exposure chamber shaking}

Species-specific sensitivity to physical stress potentially encountered during transport to the field or while deployed was evaluated for $48 \mathrm{~h}$ in laboratory chamber shaking experiments. Experiments were conducted using shakers set at three different speeds: 0 (control), 100, and 150 RPM. In situ chambers (Burton et al., 2005) were securely held (vertically) in $400 \mathrm{~mL}$ glass beakers containing $200 \mathrm{ml}$ uncontaminated, filtered $(0.45 \mu \mathrm{m})$ natural seawater $\left(30 \%\right.$ ), held at a temperature of $20{ }^{\circ} \mathrm{C}$. Chambers were open on top, therefore, it is expected that this exposure scenario represented worst-case conditions, as significant water motion and splashing would be reduced in capped, air tight, deployed chambers. Concurrent to the shaking experiments, additional in situ chambers (with both ends capped) were deployed at a depth of $1 \mathrm{~m}$ off of the SSC Pacific research pier in San Diego Bay (average temperature of $16{ }^{\circ} \mathrm{C}$ and salinity of $33 \%$ during deployment), which receives moderate levels of small boat and ship traffic. Three test species were employed in these experiments: $5 \mathrm{~mm}$ cultured amphipods (Leptocheirus plumulosus), cultured juvenile (3 day old) mysid shrimp (Americamysis bahia), and $<4$ h old mussel (M galloprovincialis) embryos obtained from gravid adults using standard methods (USEPA, 1995). Amphipod and mysid chambers each held 10 organisms, while mussel chambers held approximately 200 embryos. A minimum of three replicate chambers were used for each treatment.

\subsection{Deployment approach}

The SEA Ring (Patent No. US 8,011,239 BI. 2011) consists of a circular carousel capable of housing an array of in situ toxicity and bioaccumulation chambers, passive sampling devices, and water quality sensing devices (Fig. 1). The main platform is a carousel of $1 / 2$ " acrylic. The base and top of the carousel are circular in shape with diameters of 17 and $13^{\prime \prime}$, respectively. The base portion has 14 circular cutouts. A $5 \frac{1}{2} 2$ "-long cylindrical chamber holder is glued into each cutout, and serves as a means of housing the individual exposure chambers. Each chamber holder has 12 vertically oriented cutouts approximately $3^{\prime \prime}$ long by $1 / 2$ " wide so as to maximize water flow across the mesh covered exposure chambers while maintaining structural rigidity of the holder.

The exposure chambers were designed for conducting water column (WC) sediment-water interface (SWI), or surficial sediment (SED) exposures (Fig. 2). The WC and SWI exposure chambers are $5^{\prime \prime}$ long, while the SED chambers are $10^{\prime \prime}$ long. Exposure chambers were modified designs of Anderson et al. (2004) and Burton et al. (2005). The WC and SWI chambers were maintained above the sediment surface with acrylic stops that were glued onto the bottom inside lip of the chamber holders, while the SED chambers extended approximately $5^{\prime \prime}$ below the base portion of the SEA Ring in the sediment. Exposure chambers were made of cellulose acetate butyrate cylindrical tubing. Chambers used for housing smaller organisms such as amphipods, polychaetes, mysids, or bivalve embryos each possess two mesh cutouts approximately $2^{3} / 4$ " tall by $1^{3} / 4$ " wide. Mesh pore size was typically $250-500 \mu \mathrm{m}$, except for bivalve embryos ( $25 \mu \mathrm{m}$ mesh). Mesh was fastened to the cutouts with aquarium grade silicone glue. Exposure chambers housing larger organisms (i.e., adult bivalves) typically utilized chambers to which $1 / 8^{\prime \prime}$ holes were drilled approximately every $3 / 4$ " around and down the tube to maximize water flow, and did not require mesh. Exposure chamber contents were enclosed using polyethylene end caps $\left(2^{3} / 4\right.$ " diameter). The bottom cap on SWI chambers was modified by placing a circular mesh covered acrylic ring inside an end cap to which a $21 / 2$ " circular cutout was made to allow for exposure to potential contaminant flux at the sediment-water interface. The SED chambers housing smaller organisms were open at the bottom, and capped from the bottom prior to recovery by divers, while the chambers for larger organisms were fitted with a coarse $1 / 2$ " stainless steel mesh over the bottom.

Custom holders were designed for the SED chambers that allowed DGT probes to be deployed within SEA Rings. The holders position the DGT vertically so that the majority of the device is buried in the sediment during deployment, with $\sim 2 \mathrm{~cm}$ remaining in the water column to provide both a shallow porewater and overlying water measurement. The SPME samplers were deployed adjacent to the SEA Ring.

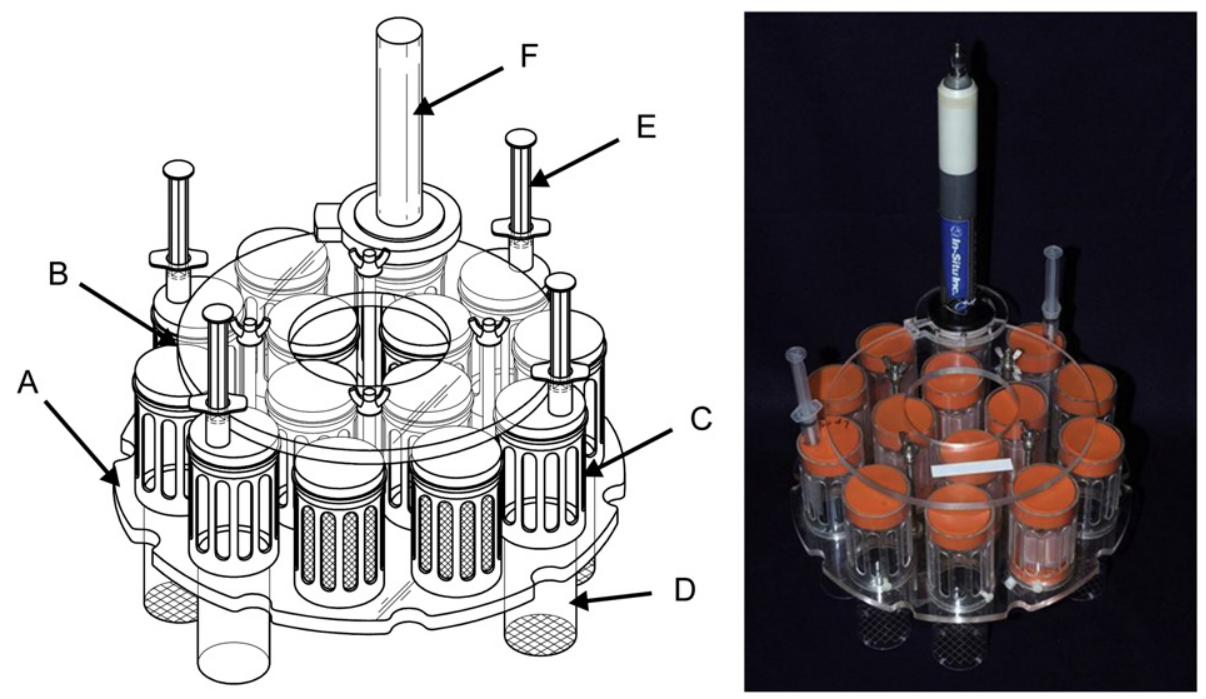

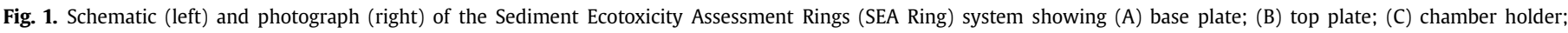
(D) exposure chamber; (E) syringe for dispensing sediment dwelling organisms; and (F) in situ water quality sensor. 


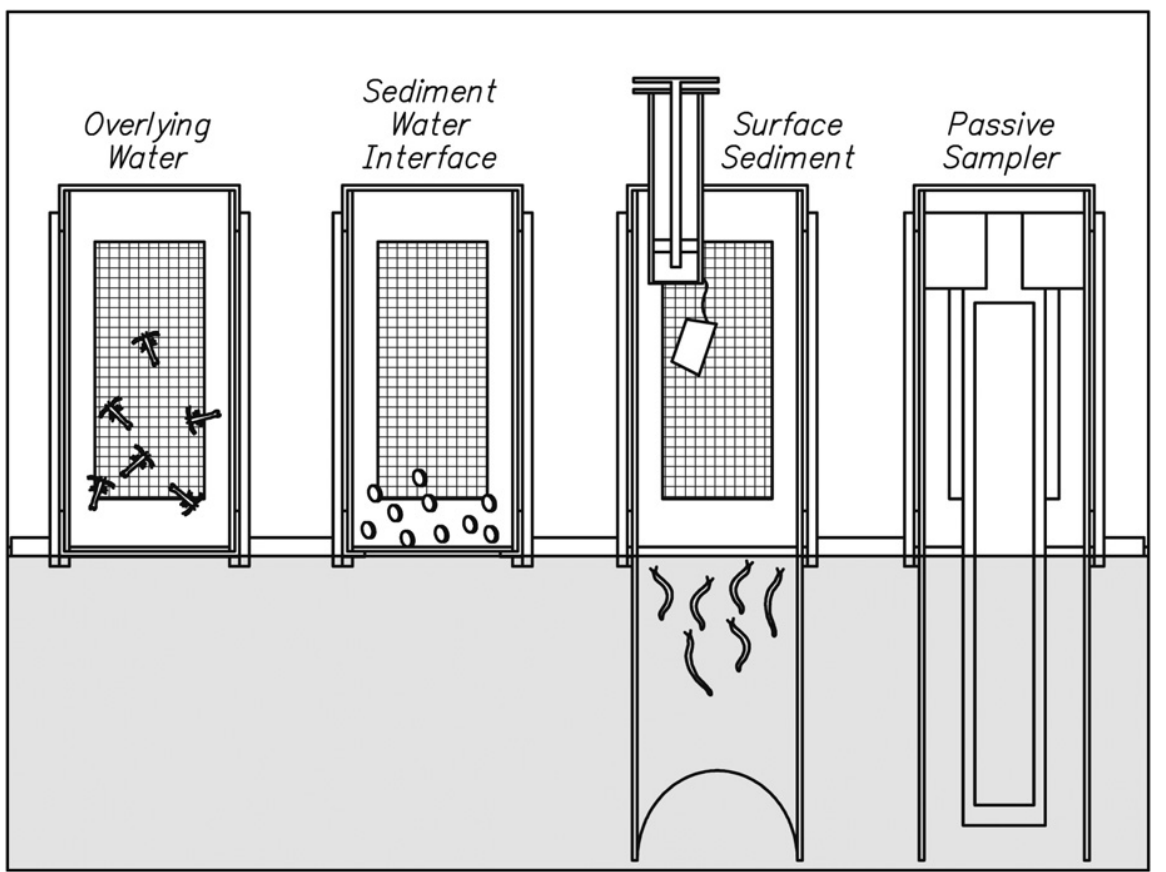

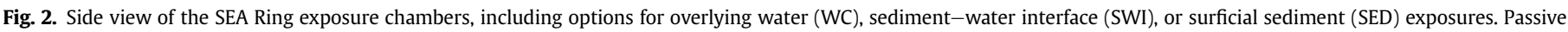
samplers are also integrated into chambers, as shown for DGT.

An exposure chamber adapter was also developed to allow continuous monitoring of water quality onboard the SEA Ring using a portable Troll ${ }^{\circledR} 9500$ (In Situ, Inc.) multi-parameter water quality monitoring and logging instrument. This allowed for monitoring of various water quality parameters (i.e., $\mathrm{pH}$, temperature, salinity, dissolved oxygen, ORP, and depth) not only on the sea floor, but specifically inside a chamber that represented conditions encountered by the test organisms.

\subsection{SEA Ring preparation and deployment}

Organisms used in WC and SWI exposures were loaded into chambers in the laboratory. This step was conducted in circular 17 gallon HDPE chambers (ChemTainer), which were also used for transportation of the SEA Rings to the field site. Smaller organisms used in SED exposures were loaded into modified 20 or $30 \mathrm{~mL}$ plastics syringes. The luer-lock portion of the syringe was removed and silicone stoppers retained the organisms in clean seawater until deployment, based on a similar design reported by Anderson et al. (2004). The loaded syringes were transported to the test site in coolers filled with seawater at the test site temperature and salinity. Travel controls were utilized to ensure there was no stress from transport in the syringes, and results indicated there was none. Immediately prior to deployment, the syringes were inserted into previously drilled holes through the top end caps. Water sampling was conducted with a $40 \mathrm{~mL}$ plastic syringe that attached to the tubing, with the sample measured immediately by field crew.

Once on site, the containers were gently lowered into the water, and the SEA Rings removed from the transport containers by divers, who placed them on the sea floor. At each station, multiple SEA Rings were deployed to account for differing exposure periods $(2-21 \mathrm{~d})$. For SED exposure chambers, syringe stoppers were popped by depressing the plungers, thus releasing the organisms.

\subsection{Recovery approach}

Deployments were recovered by divers by first assessing the overall condition of the exposure chambers and removing overlying water quality samples through top cap sampling ports for immediate measurements of $\mathrm{pH}$, temperature, salinity, DO and ORP. The open (bottom) end of SED chambers were capped by gently covering with polyethylene (PE) end caps with the SEA Ring still in place. The SEA Rings were placed into the appropriate ChemTainer and brought back up to the boat, then transferred back to the laboratory for processing.

\subsection{Summary of the San Diego bay deployment as a proof-of-concept}

\subsubsection{Test site}

Located on San Diego Bay, CA, several pier areas at Naval Base San Diego (NBSD) have been listed as potentially at risk for aquatic life impacts. A transect between piers 5 and 6 was selected based on historical data for evaluation of integrated in situ assessment tools including short-term toxicity and bioaccumulation testing (Table 1, Fig. 3 ).

\subsubsection{Bulk sediment analysis}

Sediments captured in the SED chambers were analyzed for physical and chemical characteristics. Grain size analysis of sediment samples for gravel, sand, silt and clay fractions were determined using combined sieve and sedimentation techniques. Sediment samples were analyzed for total organic carbon (TOC). Bulk sediments were analyzed for a suite of metals, PAHs, PCBs, and chlorinated pesticides using low-level detection EPA methods. For metals, samples were digested using a mixed acid digestion technique for total metals based on EPA method 200.2. All metals, except mercury and selenium, were analyzed by either inductively coupled plasma mass spectrometry (ICP-MS) following EPA Method 200.8 or by inductively coupled plasma optical emission spectroscopy (ICP-OES) following EPA Method 200.7. Mercury was analyzed by cold vapor atomic absorption following modified EPA Method 7471.A. Selenium was analyzed by flow injection atomic absorption based on EPA Method SW846, 7000 series. Sediment samples were simultaneously extracted for PAHs, PCBs, and chlorinated pesticides, and splits were subsequently made for analysis. The sample extracts were analyzed for PAHs by a modified version of EPA's SW-846 Method 8270. The PCB congener analysis method used a modified version of EPA's SW-846 Method 8081 using dual, dissimilar columns and dual detectors.

\subsubsection{Test organisms}

A number of species representing different phyla, feeding habits, exposure routes, and endpoint sensitivities were utilized for toxicity and bioaccumulation exposures. The following organisms, and starting size or age-class, were used for toxicity tests: amphipod (Eohaustorius estuarius) survival $(3-5 \mathrm{~mm})$, mysid shrimp (A. bahia) survival (3-5 days old), polychaete (Neanthes arenaceodentata) survival and post exposure feeding rate ( 6 week old), and mussel (M. galloprovincialis) embryo-larval

Table 1

Assessment methods (Lines-of-Evidence) used at the Naval Base San Diego.

\begin{tabular}{|c|c|}
\hline $\begin{array}{l}\text { SEA ring supported } \\
\text { lines-of-evidence }\end{array}$ & Lines-of-evidence used for Naval Base San Diego \\
\hline Toxicity & $\begin{array}{l}\text { E. estuarius (SED) } \\
\text { N. arenaceodentata (SED) } \\
\text { M. galloprovincialis (SWI) } \\
\text { A. bahia (SWI, WC) }\end{array}$ \\
\hline Bioaccumulation & $\begin{array}{l}\text { M. senhousia (SED) } \\
\text { N. arenaceodentata (SED) }\end{array}$ \\
\hline Passive Samplers & $\begin{array}{l}\text { SPME } \\
\text { DGT }\end{array}$ \\
\hline Bulk Sediment Chemistry & $\begin{array}{l}\text { metals, PAHs, PCBs, pesticides, grain size, } \\
\text { total organic carbon }\end{array}$ \\
\hline Water quality & $\begin{array}{l}\text { Continuous monitoring with In Situ, Inc. } \\
\text { Troll }{ }^{\circledR} 9500\end{array}$ \\
\hline
\end{tabular}




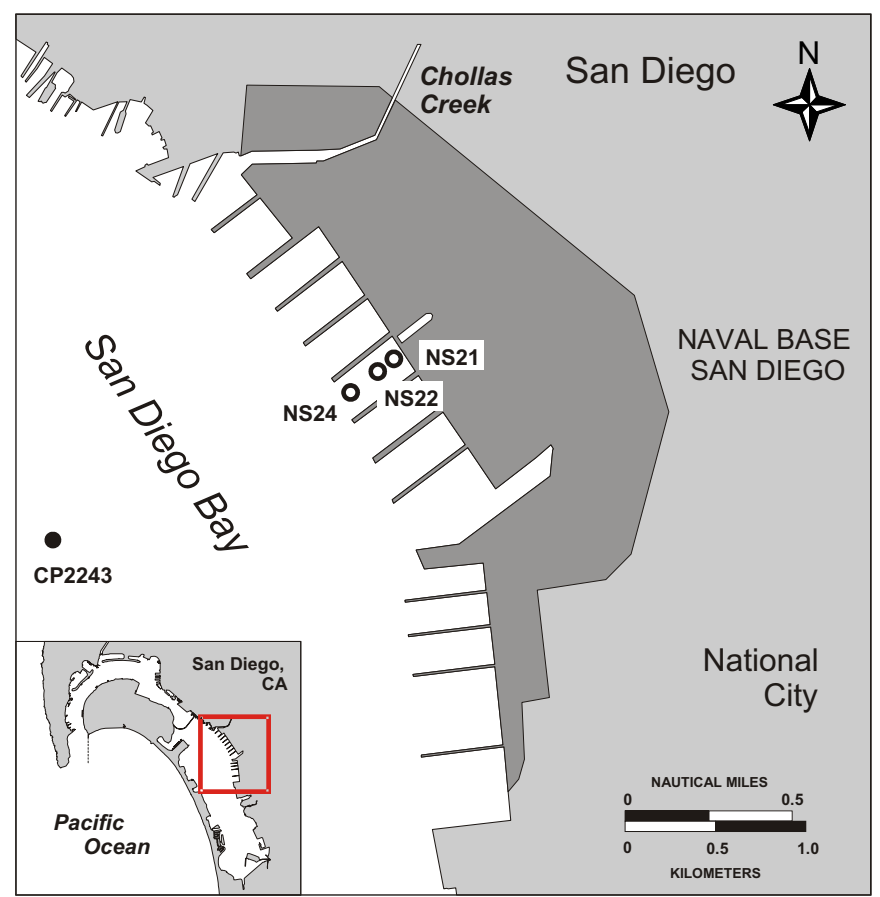

Fig. 3. Study sites for the San Diego Bay deployments.

development. Bioaccumulation chambers included infaunal mussels Musculista senhousia $(2 \mathrm{~cm})$ and 6 week old polychaetes ( $N$. arenaceodentata). All test organisms were shipped overnight to the relevant laboratory and acclimated in uncontaminated seawater adjusted to the approximate site conditions for $24-48 \mathrm{~h}$ prior to deployment. All organisms were provided by commercial suppliers, and with the exception of the mysid shrimp and polychaete, were field collected.

\subsubsection{Controls and reference sites}

Laboratory toxicity tests included control sediment, which consisted of the home sediment for E. estuarius (Yaquina Bay, OR). Laboratory control and dilution water was $0.45 \mu \mathrm{m}$ filtered seawater from the research piers at Scripps Institution of Oceanography (La Jolla, CA) or SSC Pacific (near the mouth of San Diego Bay). In situ exposures typically included both a laboratory and a travel control. Travel controls were treated the same as in situ deployed organisms in that they were caged and transported to the site, but instead of being deployed, they were held in the laboratory exposures for the duration of the field exposures. A single reference station was used (CP2243) where low chemistry and toxicity and healthy benthic communities had been observed in historical data (SCCWRP and SSC San Diego, 2005).

\subsubsection{Toxicity exposures}

In situ toxicity test durations included 2-day (amphipod, polychaete, mysid and bivalve) and 10-day (amphipod) exposures. Endpoints included amphipod survival, mysid survival, bivalve embryo-larval development, and polychaete survival and post exposure feeding rate. The feeding rate assay using $N$. arenaceodentata was developed as a relevant short-term sublethal endpoint using a standardized test organism (Rosen and Miller, 2011). The endpoint is consumption rate of Artemia sp. nauplii per hourm, assessed in the lab, following a field exposure. Toxicity assessment for all tests was conducted immediately upon return to the laboratory (within 30 min of diver SEA Ring retrieval). Survivors were enumerated immediately upon recovery from chamber or sieves. The post exposure feeding rate assessment was initiated following a $1 \mathrm{~h}$ acclimation period to laboratory conditions in clean seawater, while mussel larvae were preserved in buffered formalin for later microscopic examination.

\subsubsection{Bioaccumulation exposures}

Exposure durations were evaluated at two days for $N$. arenaceodentata and 21 days for $M$. senhousia. Organisms exposed in situ were kept in clean seawater 4-18 h to clear gut contents yet prevent excessive elimination or transformation of lighter weight contaminants, and frozen for extraction and analysis. A micro-scale technique (Jones et al., 2006) was used to analyze the relatively small tissue masses generated in the in situ exposure $(0.3-1 \mathrm{~g})$ for polycyclic aromatic hydrocarbons (PAHs) and polychlorinated biphenyls (PCBs) total body residue.

\subsubsection{Passive sampler - SPME}

Solid phase microextraction devices (SPMEs) utilizing polydimethyl siloxane (PDMS) coated glass fibers were included as an indicator of relative biaoavialbility for organic contaminants. The PDMS fibers used in this study were FG 230/210 fibers
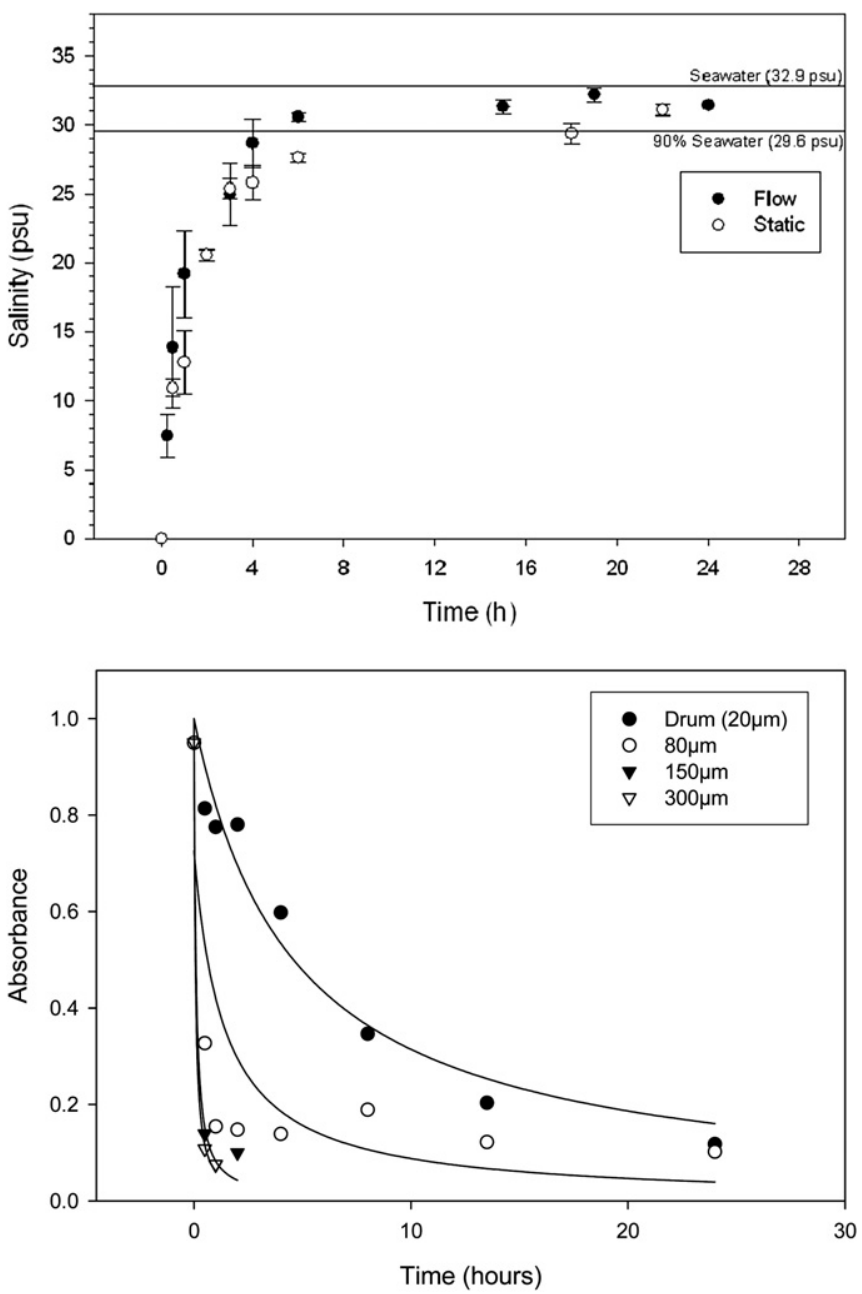

Fig. 4. Exposure chamber equilibration experiment results from multiple screen types using dye (bottom) and a prototype small mesh $(20 \mu \mathrm{m})$ scintillation vial based chamber using salinity (top) to assess time to equilibrate with external environment.

and had a $210 \mu \mathrm{m}$ core with a $10 \mu \mathrm{m}$ PDMS coating resulting in an outer diameter of $230 \mu \mathrm{m}$. The fibers were housed in small diameter $(\sim 0.25 \mathrm{inch})$ stainless steel tubes with micro-slots along their length to allow communication with the porewater and surface water. For the in situ assessment, they were deployed in tandem with the SEA Rings, positioned around perimeter within close ( $\sim 1-2$ inches) proximity to the bioaccumulation exposure chambers. SPME deployment periods were two and 21 days. Upon retrieval, the PDMS fibers were immediately cleaned, processed into solvent in 5-cm intervals, and analyzed for PAHs. PAH analysis of the PDMS material was performed at the University of Texas at Austin (UT) using high performance liquid chromatography for separation with fluorescence detection (HPLC/FD) for quantification, in accordance with EPA Method 8310 using a Waters 2795 Separations Module. The total organic carbon (foc) of sediment samples was determined by elemental analysis on a Carlo-Erba 1108 (i.e., overnight vapor acidification with a hydrochloric acid atmosphere to remove inorganic carbon from samples).

\subsubsection{Passive sampler- DGT}

Diffusive gradients in thin film (DGT) accumulate a variety of dissolved "labile" substances, including metals (DGT Research Ltd.). DGT removes dissolved components from porewater in a similar fashion to uptake by biological organisms, and the concentration at the porewater-DGT interface $\left(\mathrm{C}_{\mathrm{DGT}}\right)$ provides a relative measure of the uptake of bioavailable metals that is a more accurate measure of sediment metal toxicity than sequential extraction methods. Commercially available DGT probes consisting of a diffusive gel protected by a plastic housing (Zhang et al., 2001) were used. Custom holders were fitted to SED chambers that allowed DGT probes to be deployed within SEA Rings (Fig. 2) at each of the four stations. They were inserted into sediments such that about two thirds of the device was within the sediment and the top third was within the water column. Exposure duration was two days. Upon recovery of the SEA Rings, DGTs were removed from their holders, and rinsed thoroughly in deionized water to remove all traces of sediment. Acidified water samples were shipped to an outside laboratory (Alloway Laboratory, Lima, $\mathrm{OH}$ ) and 

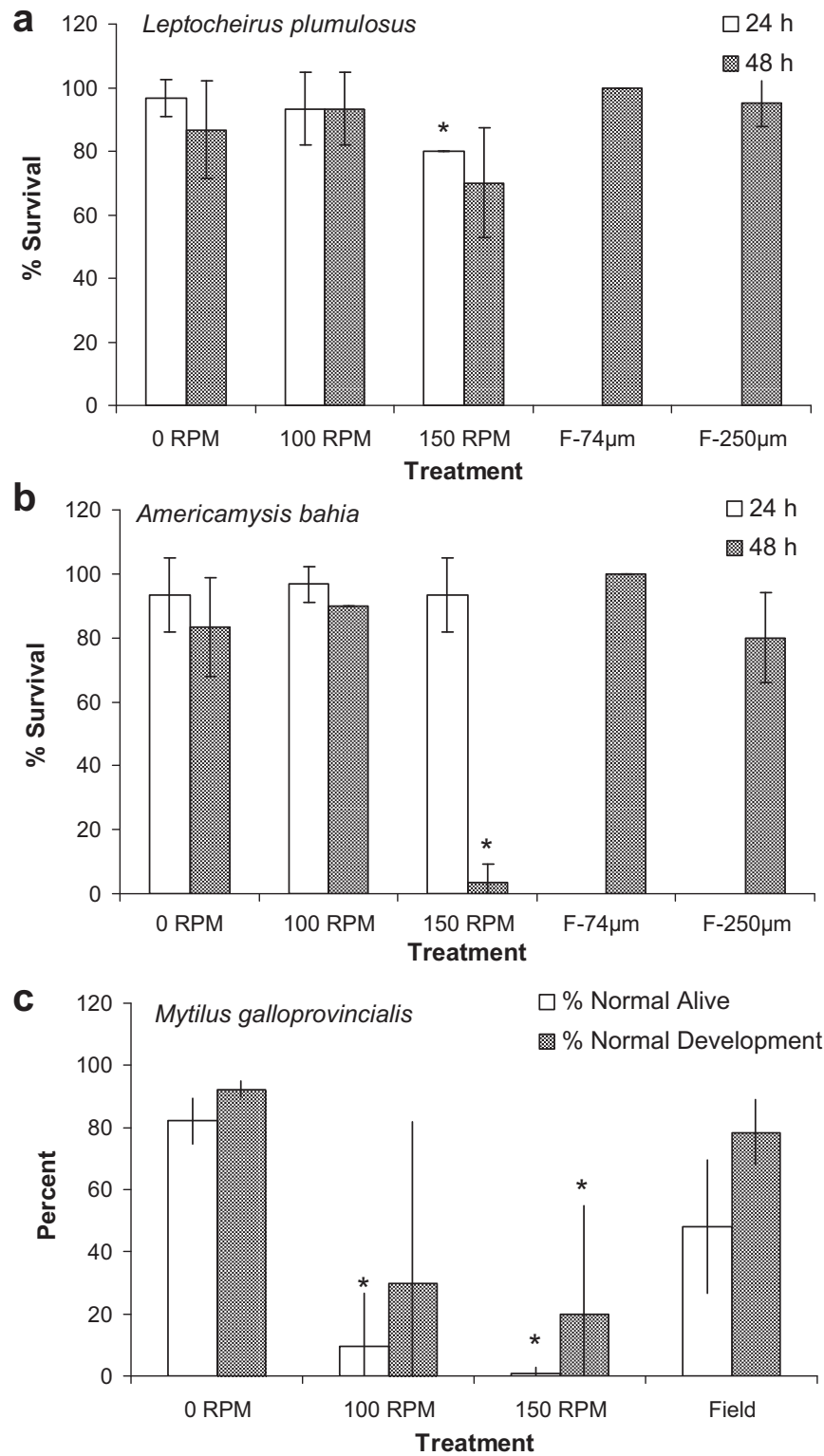

Fig. 5. Shaker study results for Leptocheirus plumulosus (a), Americamysis bahia (b), and Mytilus galloprovincialis (c). F-74 $\mu \mathrm{m}$ and F-250 $\mu \mathrm{m}$ represent Field exposure in exposure chamber with 74 and $250 \mu$ m mesh windows, respectively, which were only recorded at $48 \mathrm{~h}$. All M. galloprovincialis exposures were conducted with $20 \mu \mathrm{m}$ mesh windows. analyzed for $\mathrm{Cu}, \mathrm{Zn}, \mathrm{Ni}, \mathrm{Pb}$, and Cd using EPA method 200.8 (USEPA, 1994b). Dissolved metal concentrations were ultimately converted to DGT concentrations $\left(C_{D G T}\right)$ using temperature specific diffusion coefficients provided by the DGT manufacturers.

\section{Results and discussion}

\subsection{Preliminary testing}

The dye study showed rapid equilibration between the inside of the exposure chambers and the external environment with only $10 \%$ of the dye remaining after $30 \mathrm{~min}$ for the 150 and $300 \mu \mathrm{m}$ screen sizes, and $1 \mathrm{~h}$ for the $80 \mu \mathrm{m}$ screen size (Fig. 4). The $25 \mu \mathrm{m}$ drum chamber housed inside an $80 \mu \mathrm{m}$ screen chamber took the longest to equilibrate requiring between 13.5 and $24 \mathrm{~h}$ to achieve the same degree of equilibration. The overall rapid equilibration observed suggests that conditions inside the in situ exposure chambers mimics the external environmental well, even over short exposure durations.

Similarly, the modified scintillation vial chamber design considered for small $(25-80 \mu \mathrm{m})$ organisms such as mussel embryos showed rapid equilibration using salinity as a surrogate for a contaminant (Fig. 4). Within $4 \mathrm{~h}$, salinity within the vials was 79 and $88 \%$ of the salinity in the external environment for static and flow through conditions, respectively (Fig. 4). Steady-state (90\%) conditions were achieved within $6 \mathrm{~h}$ under the flow conditions, and by the $18 \mathrm{~h}$ time-point under static conditions. Rapid equilibration is particularly important for short (i.e. two day) exposures.

Results of the chamber shaking experiments showed L. plumulosus and $A$. bahia were unaffected at 100 RPM after $48 \mathrm{~h}$, but some reduced survival was observed (at $48 \mathrm{~h}$ only) for both species at 150 RPM (Fig. 5). The $48 \mathrm{~h}$ reduced survival at 150 RPM was particularly apparent for $A$. bahia (mean survival $=3.3 \pm 5.8 \%$ ), suggesting that they are less tolerant than $L$. plumulosus (mean survival $=$ $70 \pm 17 \%$ ) to physical stress. L. plumulosus, which are considerably larger than A. bahia, concentrated near the bottom of the containers during exposure. It should be noted, however, that the controlled shaking studies may have been overly stressful due to the fact that concurrent $48 \mathrm{~h}$ pierside in situ deployments in an area with reasonable high boat traffic yielded high survival for both species at both time points ( $\geq 80 \%$; Fig. 5).

Mussel (M. galloprovincialis) embryo-larval development shaking results generally showed a substantial reduction in the number of normally developed larvae relative to the initial number of embryos added (\% normal alive) and the percent normally developed of those counted (\% normal development) (Fig. 5), with the former being a somewhat more sensitive endpoint to physical stress. The pierside in situ deployments yielded higher embryo-larval development than

Table 2

Bulk sediment concentrations summary at Naval Base San Diego.

\begin{tabular}{|c|c|c|c|c|c|c|c|}
\hline \multirow[t]{2}{*}{ Analyte } & \multirow[t]{2}{*}{ Units } & \multicolumn{6}{|c|}{ Site/Station } \\
\hline & & $\overline{E R L}$ & ERM & NS21 & NS22 & NS24 & $\mathrm{CP} 2243^{\mathrm{a}}$ \\
\hline Cadmium & $\mathrm{mg} / \mathrm{kg}$ & 1.2 & 9.6 & 0.354 & 0.267 & 0.669 & 0.136 \\
\hline Chromium & $\mathrm{mg} / \mathrm{kg}$ & 81 & 370 & 81.1 & 94.5 & 79.7 & 48.0 \\
\hline Copper & $\mathrm{mg} / \mathrm{kg}$ & 34 & 270 & 277 & 316 & 197 & 79.8 \\
\hline Mercury & $\mathrm{mg} / \mathrm{kg}$ & 0.15 & 0.71 & 0.76 & 0.91 & 0.79 & 0.35 \\
\hline Lead & $\mathrm{mg} / \mathrm{kg}$ & 46.7 & 218 & 73.9 & 75.4 & 63.2 & 33.3 \\
\hline Zinc & $\mathrm{mg} / \mathrm{kg}$ & 150 & 410 & 342 & 338 & 308 & 159 \\
\hline Total Chlordane & $\mu \mathrm{g} / \mathrm{kg}$ & & & 0.600 & 0.420 & 0.820 & 0.04 \\
\hline Total DDTs & $\mu \mathrm{g} / \mathrm{kg}$ & 1.58 & 46.1 & 6.32 & 6.62 & 7.41 & 0.88 \\
\hline Total PAH & $\mu \mathrm{g} / \mathrm{kg}$ & 4022 & 44,792 & 5214 & 5105 & 2924 & 415 \\
\hline Total PCB & $\mu \mathrm{g} / \mathrm{kg}$ & 22.7 & 180 & 234 & 172 & 207 & 21.4 \\
\hline Silt/Clay & $\%$ & & & 72.5 & 85.9 & 67.1 & 40.9 \\
\hline TOC & $\%$ & & & 2.01 & 2.14 & 1.58 & 0.710 \\
\hline
\end{tabular}

$\mathrm{ERL}=$ effects-range-low; ERM = effects-range-median (MacDonald et al. 1996)

No data shown where not measured or not applicable.

a Reference station. 
shaking, which was not significantly different from laboratory controls. The experimental shaking exposure scenario (open top, with high turbulence) is unlikely in closed field-deployed exposures. Greater variability among replicates with caged M. galloprovincialis embryos relative to standard static laboratory exposures was also observed in microcosm experiments by Rosen and Lotufo (2010).

\subsection{Proof-of-concept - San Diego deployment results}

Multiple lines-of-evidence were investigated in this study in this first major deployment of the SEA Rings. Linkage of exposure and effects was assessed. The second part of this paper series (Rosen et al., 2012) elaborates on the importance of these linkages at a site where multiple contaminant pathways of exposure were possible. Bulk sediment concentrations for sediments captured in the SEA Rings are summarized in Table 2, and are compared to sediment quality guidelines i.e., Effects Range Low [ERL] and Effects Range Median [ERM] parameters; MacDonald et al. (1996). The results show a general increasing trend toward the shoreline for PAHs, but overall, similar values exist among stations for the other chemicals of concern. Highest concentrations of $\mathrm{Ch}, \mathrm{Pb}, \mathrm{Zn}$, chlordane, total DDTs and total PAHs generally were between the ERL and ERM values. The highest concentrations of $\mathrm{Cu}, \mathrm{Hg}$ and PCBs generally exceeded the ERM and $\mathrm{Cd}$ was below the ERL. These screening-level thresholds suggest a reasonable potential for toxicity. In contrast, concentrations at the reference station (CP2243) were always lower by a factor of two to one order of magnitude and were below ERMs.

Toxicity from field exposures was lower than expected based on bulk sediment contaminant concentrations and historical data at the site (SCCWRP and SSC San Diego, 2005). Two-day in situ exposures resulted in $\geq 90 \%$ survival at the reference site (CP2243) for both $E$. estuarius and A. bahia, while $N$. arenaceodentata mean survival was $75 \%$ (Table 3 ).

No toxicity (survival $\geq 97.5 \%$ ) was observed at any station in A. bahia exposures of the water column (Table 3), indicating relative robustness of this test organism for use in situ and the sediments as the more likely adverse exposure route. Clark et al. (1987) also reported successful use of $A$. bahia in field exposures.

On the contrary, M. galloprovincialis larval recovery from in situ SWI exposures was low and variable for all stations including the reference (Table 3). Water quality from the Troll 9500 sensors are shown in Table 4, and show acceptable conditions for all organisms used in this study. The water quality data, however, are representative of conditions at the SWI in SED chambers with a $250 \mu \mathrm{m}$ mesh size. Based on discrete water quality measurements made on individual M. galloprovincialis chambers, which utilized a $25 \mu \mathrm{m}$ screen, D.O. concentration was markedly reduced $(<1 \mathrm{mg} / \mathrm{L})$ and contents of some of those chambers smelled strongly of sulfides. It is likely that flow through the mussel chambers was inhibited due to clogging by fine sediment particles. In addition to water quality related artifacts, microscopic assessment of the mussel samples was extremely difficult due to aggregated particulate matter of similar size to the larvae. Therefore, non-contaminant related artifacts likely contributed to the heightened sensitivity of the fielddeployed mussel embryos.

Although one goal of this work was to develop a rapid on-site assessment protocol, E. estuarius were also exposed for 10 days in situ, which is the standard duration for acute exposures in the laboratory (USEPA, 1994a). Recoveries of E. estuarius after 10 days of exposure were relatively poor (averaging $<40 \%$; Table 3 ), but still showed a greater response at station NS21, consistent with the 2-day data and increased risk associated with other lines-of-evidence. Temperatures during the 10-day exposure reached $24{ }^{\circ} \mathrm{C}$, which likely were in excess of that tolerated by E. estuarius, traditionally

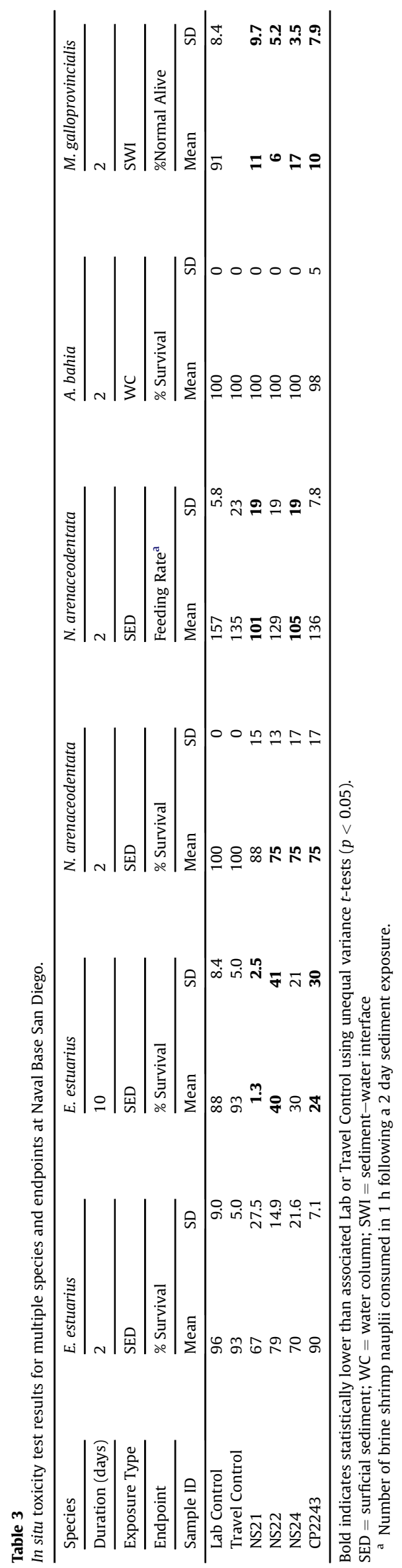


Table 4

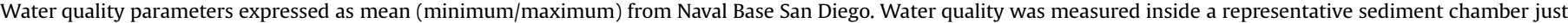

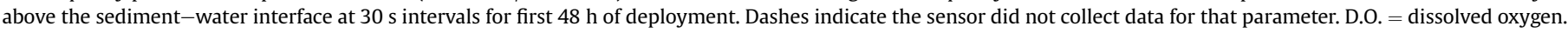
$\mathrm{ORP}=$ oxidation-reduction potential.

\begin{tabular}{|c|c|c|c|c|c|c|c|}
\hline Station & Temperature $\left({ }^{\circ} \mathrm{C}\right)$ & Depth (m) & D.O. (mg/L) & $\mathrm{pH}$ & Salinity (\%) & Conductivity $(\mathrm{mS} / \mathrm{cm})$ & ORP $(\mathrm{mV})$ \\
\hline NS21 & $22.3(21.4 / 22.8)$ & $10.5(9.4 / 11.6)$ & $5.7(4.0 / 7.1)$ & $6.8(6.8 / 7.0)$ & $35.7(35.1 / 36.1)$ & $51.2(49.7 / 52.1)$ & $84(-156 / 164)$ \\
\hline NS22 & $22.2(21.3 / 22.8)$ & $10.2(9.1 / 11.3)$ & $4.9(3.1 / 7.3)$ & $7.6(7.3 / 7.9)$ & $33.1(32.7 / 33.3)$ & $47.8(46.4 / 48.5)$ & $194(-72 / 254)$ \\
\hline NS24 & $22.6(21.7 / 23.3)$ & $11.2(10.0 / 12.3)$ & $5.6(4.3 / 6.4)$ & $7.7(7.4 / 7.9)$ & $34.0(33.4 / 34.4)$ & $49.3(47.7 / 50.5)$ & $159(-84 / 234)$ \\
\hline $\mathrm{CP} 2243^{\mathrm{a}}$ & $23.1(22.5 / 23.7)$ & $4.7(3.5 / 5.8)$ & $7.1(6.5 / 8.2)$ & $7.9(7.7 / 8.0)$ & $33.4(31.7 / 36.0)$ & $49.0(46.8 / 52.6)$ & - \\
\hline
\end{tabular}

a Reference station.

tested at $15{ }^{\circ} \mathrm{C}$ (USEPA, 1994a). Results for the 2-day bivalve larvae SWI and 10-day amphipod SED exposures suggest these tests require more refinement to achieve reliable results.

Other lines-of-evidence to assess bioavailability included the passive samplers and polychaete and mussel bioaccumulation. DGT-data in the top $5 \mathrm{~cm}$ of the sediment (Fig. 6) generated predicted porewater concentrations $\left(\mathrm{C}_{\mathrm{DGT}}\right.$ ) ranging from 1.1 to $3.1 \mathrm{mg} / \mathrm{m}^{3}$ for copper and $4.2-16.3 \mathrm{mg} / \mathrm{m}^{3}$ for zinc. While the spatial trend was generally consistent with the observed gradients in bulk sediment and toxicity, the concentrations are generally well below dissolved metal levels that would be expected to cause toxicity to E. estuarius or $N$. arenaceodentata (McPherson and Chapman 2000; Rosen and Miller, 2011). A relationship between $C_{D G T}$ and toxicity for these metals was not apparent.

The 21-day deployment of the infaunal mussel M. senhousia, and $N$. arenaceodentata, yielded satisfactory to relatively poor survival (74 and $42 \%$ overall, respectively) for body burden determinations. Metal bioaccumulation for in situ exposures of mussels showed tissue concentrations ranging from about 3 to $12 \mu \mathrm{g} / \mathrm{g}$ dw for copper and $8-13 \mu \mathrm{g} / \mathrm{g}$ for zinc, with lowest concentrations measured at the reference station, CP2243. Together, these lines-of-evidence for metal bioavailability indicate limited metals bioavailability consistent with observed contamination gradients and limited toxicity.

Porewater concentrations of PAHs from the in situ SPME samplers were evaluated in relation to bioaccumulation in mussels (Fig. 7). Both lines-of-evidence showed a consistent pattern with higher porewater and tissue concentrations at stations NS21 and NS24, lower levels at NS22, and lowest levels at the reference station

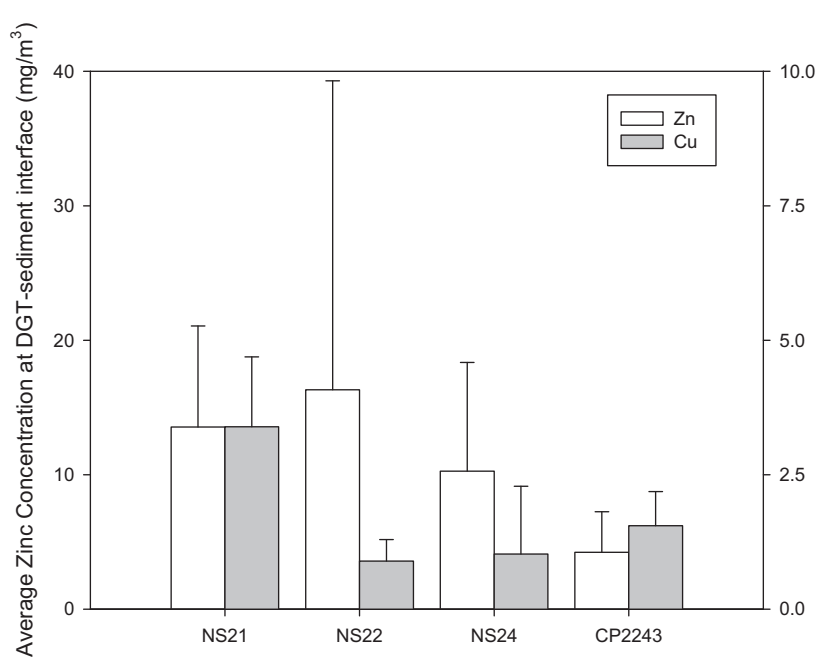

Fig. 6. Concentrations of metals measured using diffusive gradient thin films (DGT) probes at the porewater-DGT interface $\left(\mathrm{C}_{\mathrm{DGT}} ; \mathrm{mg} / \mathrm{m}^{3}\right)$. Reported concentrations from DGT probes are averaged across the top $5 \mathrm{~cm}$ of the sediment. Error bars = range values in one $\mathrm{cm}$ slices of $5 \mathrm{~cm}$. Open bars are zinc concentrations; solid bars are copper concentrations.
CP2243. This bioavailability evidence, when compared to the acute toxicity to E. estuarius and $N$. arenaceodetnata, provides a different perspective from the bulk sediment chemistry, which showed a monotonic increase toward the shoreline. The relatively higher bioavailability at NS21 might help explain the increase in toxicity observed at this station, while the overall absence of toxicity at NS22 is supported by relatively low bioavailability measures including the in situ tissue and passive sampler measurements, particularly with respect to PAHs.

Overall, however, results from the in situ tests indicate a weak gradient of response corresponding roughly with the increasing concentration gradient toward the shoreline. This suggests contaminants at the site have a low degree of bioavailability.

\subsection{Refinements}

Several ongoing refinements to the prototype SEA Rings were made following lessons learned from this initial site deployment. This included incorporation of a re-circulating water pump system and several modifications to improve reliability and reduce dependence on diver support. Initial deployments, particularly those with small mesh and/or extended exposure duration, indicated that at more biologically productive sites, screens fouled and reduced water flow and water quality. Subsequent exposures included an integrated water circulation system to increase surface water flow through the chambers and thereby reduce the likelihood of dissolved oxygen sags within the chambers. A small (2 watt) submersible pump was

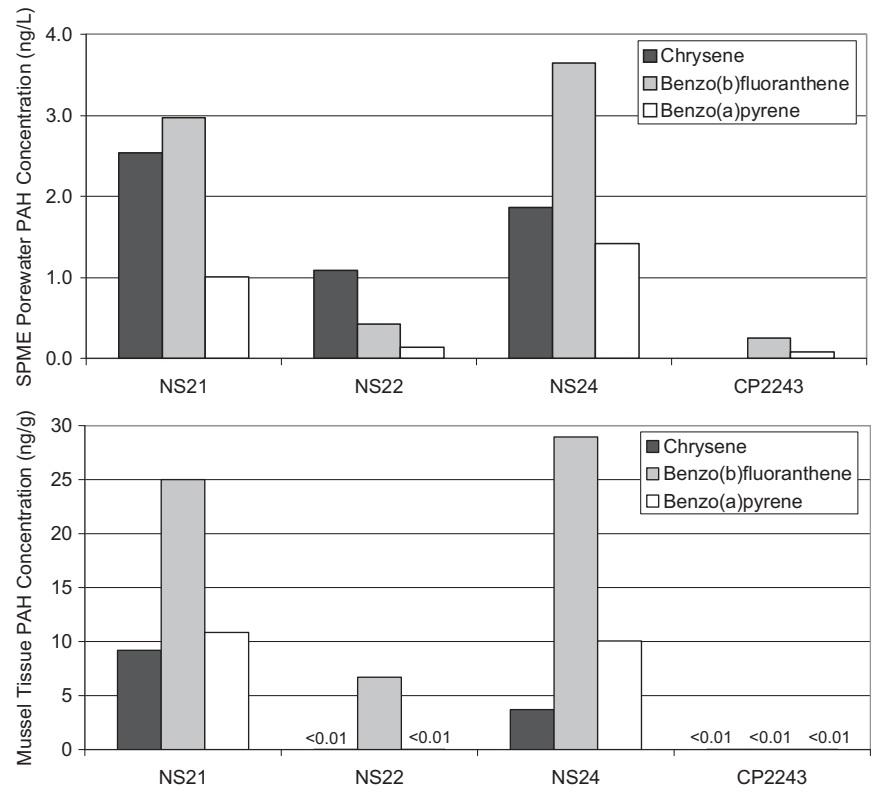

Fig. 7. Porewater concentrations of PAHs from the SPME samplers (above), and bioaccumulation in 21-day mussel exposures (below). Reported porewater concentrations from PAHs are averages across the top $7 \mathrm{~cm}$ of the sediment. 
attached to a custom-built waterproof battery housing. Tygon tubing gently sprayed site water through small holes in the tubing placed external but adjacent to exposure chamber windows on the interior of the SEA Ring. Reduced diver dependence was achieved by incorporating a bracket to the top portion of the SEA Ring to which a series of poles could be inserted for deployment from a boat. Once adequately positioned on the sediment surface, a pin attached by a line was pulled allowing the pole to be pushed to a second tier, which triggered release of SED test organisms housed in the modified plastic syringes. Recovery of open-bottomed SED chambers was addressed by modifying the PE end caps with a series of crosssectional slices (kept open with an acrylic ring during deployment) that served much like a core catcher, trapping sediment and test organisms when pulled from the sediment, but preserving the stratification of the sediment during the field exposure

\section{Conclusions}

The scale and scope of sediment-related risk assessment projects is often enormous and there is a tendency to use overly simplistic bulk chemistry analysis and comparisons to sediment quality guidelines that do not consider factors affecting bioavailability and do not account for co-occurrence issues. This practice is not supported scientifically and should only be used as a crude Tier 1 assessment, followed by an assessment based on multiple linesof-evidence (e.g., habitat, laboratory and in situ-based toxicity, indigenous biota) (Adams et al., 2005; Wenning et al., 2005). The SEA Ring approach described here reduces the uncertainty around sediment risk assessments and remedial decision-making, because it provides for simultaneous analysis of chemical exposure (including mixtures) and biological responses in situ. Additionally, this approach has the potential to assess impacts of noncontaminant stressors, which can be important to consider in understanding causality and evaluating remedial options.

The SEA Ring platform allowed for simultaneous deployment of multiple marine and estuarine species exposed via three compartments (overlying water, sediment-water interface, and bulk sediment) for toxicity and bioavailability measurements, along with passive samplers as indicators for metal (DGT) and non-polar organic (SPME) bioavailability, and the collection of collocated bulk sediment samples. The SEA Ring also incorporates sensors to continuously monitor water quality parameters from within the in situ exposure cages, thereby providing meaningful ancillary data with which to interpret the in situ results. The overarching goal of the approach was to improve the accuracy when assessing ecological risk and remediation efficacy at contaminated sediment sites by improving the linkage between exposure and effects, particularly in scenarios where traditional laboratory-based methods alone are inadequate to make informed management decisions, such as the assessment of in place sediment remedy effectiveness, and time-varying stressors such as storm water discharges, ground-water surface water interactions, oil spills, and unexploded ordnance assessments. The approach is rapid, and should prove cost-effective, with many of the measurements being made on-site in less than one week.

\section{Acknowledgements}

This research was funded by a grant from the Strategic Environmental Research and Development Program (SERDP), under Project \#ER-1550. The authors thank David Lampert, Patty Tuminello, Sarah Douglass, Jennifer Podegracz, Chris Stransky, Kyle Miller, Joel Guerrero, Brad Davidson, Ryan Halonen, Jon Groves, Robert Beltran, and Padrick Anderson, for their valuable contributions in the laboratory and/or field.

\section{References}

Adams, W., Green, A., Ahlf, W., Burton, A., Brown, S., Chadwick, B., Crane, M., Gouguet, R., Ho, K., Reynoldson, T., Savitz, J., Sibley, P., Ringwood, A., Hogstrand, C., 2005. Using sediment assessment tools and a weight of evidence approach. In: Wenning, R.J., Bately, G.E., Ingersoll, G.C., Moore, D.W. (Eds.), Use of Sediment Quality Guidelines and Related Tools for the Assessment of Contaminated sediments. Society of Environmental Toxicology and Chemistry, Pensacola, FL, pp. 163-226.

Anderson, B.S., Hunt, J.W., Phillips, B.M., Nicely, P.A., Tjeerdema, R.S., Martin, M.A., 2004. Comparison of in situ and laboratory toxicity tests with the estuarine amphipod Eohaustorius estuarius. Archives of Environmental Contamination and Toxicology 46, 52-60.

Burton Jr., G.A., Batley, G.E., Chapman, P.M., Forbes, V.E., Smith, E.P., Reynoldson, T., Schlekat, C.E., den Besten, P.J., Bailer, A.J., Gree, A.S., Dwyer, R.L., 2002. A weightof-evidence framework for assessing sediment (or other) contamination: improving certainty in the decision-making process. Human and Ecological Risk Assessment 8, 1675-1696.

Burton Jr., G.A., Greenberg, M.S., Rowland, C.D., Irvine, C.A., Lavoie, D.R., Brooker, J.A., Moore, L., Raymer, D.F.N., McWilliam, R.A., 2005. In situ exposures using caged organisms: a multi-compartment approach to detect aquatic toxicity and bioaccumulation. Environmental Pollution 134, 133-144.

Clark, J.R., Borthwick, P.W., Goodman, L.R., Patrick Jr., J.M., Lores, E.M., Moore, J.C., 1987. Comparison of laboratory toxicity test results with responses of estuarine animals exposed to fenthion in the field. Environmental Toxicology and Chemistry 6, 151-160.

Crane, M., Higman, M., Olsen, T., Simpson, P., Callaghan, A., Fisher, T., Kheir, R., 2000. An in situ system for exposing aquatic invertebrates to contaminated sediments. Environmental Toxicology and Chemistry 19, 2715-2719.

Geffard, O., His, E., Budzinski, H., Seaman, M., Garrigues, P., 2001. In situ monitoring of sea water quality with the embryo-larval bioassay of Crasssostrea gigas and Mytilus galloprovincialis. In: Comptes Rendus de l'Acadaemie des Sciences, Saerie III, Sciences de la Vie, vol. 324, pp. 1149-1155.

Greenberg, M.S., Burton Jr., G.A., Rowland, C.D., 2002. Optimizing interpretation of in situ effects of riverine pollutants: impact of upwelling and downwelling. Environmental Toxicology and Chemistry 21, 289-297.

Jones, R.P., Millward, R.N., Karn, R.A., Harrison, A.H., 2006. Microscale analytical for the quantitative detection of PCBs and PAHs in small tissue masses. Chemosphere 62, 1795-1805.

MacDonald, D.D., Carr, R.S., Calder, F.D., Long, E.R., Ingersoll, C.G., 1996. Development and evaluation of sediment quality guidelines for Florida coastal waters. Ecotoxicology 5, 253-278.

McPherson, C.A., Chapman, P.M., 2000. Copper effects on potential sediment test organisms: the importance of appropriate sensitivity. Marine Pollution Bulletin 40, 656-665.

Phillips, B.M., Anderson, B.S., Hunt, J.W., Nicely, P.A., Kosaka, R.A., Tjeerdema, R.S., de Vlaming, V., Richard, N., 2004. In situ water and sediment toxicity in an agricultural watershed. Environmental Toxicology and Chemistry 23, 435-442.

Ringwood, A.H., Keppler, C.J., 2002. Comparative in situ and laboratory sediment bioassays with juvenile Mercenaria mercenaria. Environmental Toxicology and Chemistry 21, 1651-1657.

Rosen, G., Lotufo, G., 2007. Toxicity of explosive compounds to the marine mussel, Mytilus galloprovincialis, in aqueous exposures. Ecotoxicology and Environmental Safety 68, 237-245.

Rosen, G., Lotufo, G.R., 2010. Fate and effects of Composition B in multispecies marine exposures. Environmental Toxicology and Chemistry 29, 1330-1337.

Rosen, G., Miller, K., 2011. A post exposure feeding assay using the marine polychaete Neanthes arenaceodentata suitable for laboratory and in situ exposures. Environmental Toxicology and Chemistry 30, 730-737.

Rosen, G., Chadwick, D.B., Burton, G.A., Taulbee, W.K., Greenberg, M.S., Lotufo, G.R., Reible, D.D., 2012. A sediment ecotoxicity assessment platform for in situ measures of chemistry, bioaccumulation and toxicity. Part 2: Integrated application to a shallow estuary. Environmental Pollution 162, 457-465.

SCCWRP, SSC San Diego, 2005. Sediment assessment study for the mouths of Chollas and Paleta Creek, San Diego. Phase 1 Final Report. Prepared by the Southern California Coastal Water Research Project and Space and Naval Warfare Systems Center (SSC) San Diego. For San Diego Regional Water Quality Control Board and Commander Navy Region Southwest, May 2005, pp. 1-200.

USEPA, 1994a. Methods for Measuring the Toxicity and Bioaccumulation of Sediment Associated Contaminants with Estuarine and Marine Amphipods. U.S. Environmental Protection Agency. Office of Research and Development. EPA/600/R-94/025.

USEPA, 1994b. Method 200.8. Revision 5.4. Determination of Trace Elements in Waters and Wastes Inductively Coupled Plasma-mass Spectrometry. Environmental Monitoring Systems Laboratory. USEPA-ORD, Cincinnati, $\mathrm{OH}$.

USEPA, 1995. Short-term Methods for Estimating the Chronic Toxicity of Effluents and Receiving Waters to West Coast Marine and Estuarine Organisms. EPA/600/R-95/ 136.

Wenning, R.J., Batley, G.E., Ingersoll, C.G., Moore, D.W. (Eds.), 2005. Use of Sediment Quality Guidelines and Related Tools for the Assessment of Contaminated Sediments. SETAC Press, Pensacola, FL.

Zhang, H., Zhao, F.J., Sun, B., Davidson, W., McGrath, S.P., 2001. A new method to measure effective soil solution concentration predicts $\mathrm{Cu}$ availability to plants. Environmental Science and Technology 35, 2602-2607. 